\title{
Nuclear retention of Fbw7 by specific inhibitors of nuclear export leads to Notch1 degradation in pancreatic cancer
}

\author{
Jiankun Gao ${ }^{1,2}$, Asfar S. Azmi³, Amro Aboukameel ${ }^{2}$, Michael Kauffman ${ }^{4}$, Sharon \\ Shacham ${ }^{4}$, Abdul-Badi Abou-Samra5, and Ramzi M. Mohammad ${ }^{2,5}$ \\ ${ }^{1}$ Sichuan College of Traditional Chinese Medicine, Mianyang, Sichuan, People's Republic of China \\ 2 Department of Oncology, Karmanos Cancer Institute, Detroit, Michigan, USA \\ ${ }^{3}$ Department of Pathology, School of Medicine, Wayne State University, Detroit, Michigan, USA \\ ${ }^{4}$ Karyopharm Therapeutics, Natick MA, USA \\ ${ }^{5}$ Hamad Medical Corporation, Doha, Qatar \\ Correspondence to: Ramzi M. Mohammad, email: mohammar@karmanos.org \\ Keywords:Specific Inhibitors of Nuclear Export; Xpo 1, Exportin 1, CRM1 inhibitor; Notch1; Fbw7; Apoptosis; Pancreatic Cancer \\ Received: January 8, $2014 \quad$ Accepted:March 19, $2014 \quad$ Published: March 21, 2014
}

This is an open-access article distributed under the terms of the Creative Commons Attribution License, which permits unrestricted use, distribution, and reproduction in any medium, provided the original author and source are credited.

\section{ABSTRACT:}

Chromosome maintenance region 1 (CRM1) also called Exportin 1 (Xpo1), a protein found elevated in pancreatic ductal adenocarcinoma (PDAC), blocks tumor suppressor protein (TSP) function through constant nuclear export. Earlier we had shown that targeting CRM1 by our newly developed specific inhibitors of nuclear export (SINE) leads to inhibition of pancreatic cancer cell proliferation and tumor growth arrest. In this paper we define the mechanism of SINE action. Our lead SINE KPT185 inhibits PDAC cell growth, cell migration, tumor invasion and induces apoptosis and G2-M cell cycle arrest in low nano molar range $\left(\mathrm{IC}_{50 \mathrm{~s}} \sim 150 \mathrm{nM}\right)$. Mechanistically we demonstrate that the activity of KPT-185 is associated with nuclear retention of Fbw7; which degrades nuclear Notch-1 leading to decreased tumor promoting markers such as C-Myc, Cyclin-D1, Hes1 and VEGF. The orally bioavailable SINE (KPT251) showed potent anti-tumor activity in a Colo-357 PDAC xenografts model; residual tumor analysis showed activation of Fbw7 concomitant with attenuation of Notch 1 and its downstream genes. These results suggest that the antitumor activity of KPT185 is in part due to nuclear retention of Fbw7 and consequent Notch1 degradation. The new CRM1 inhibitors, therefore, hold strong potential and warrant further clinical investigations for PDAC.

\section{INTRODUCTION}

Pancreatic Ductal Adenocarcinoma (PDAC) is the fourth deadliest disease that accounts for $\sim 38,000$ annual deaths in the United States [1], suggesting that newer and effective treatment strategies are critically needed. The majority of PDAC patients become refractory to standard chemotherapeutic drugs such as gemcitabine and $5 \mathrm{FU}$ or their combination [2]. In principle, most chemotherapeutic drugs work through activation and nuclear localization of tumor suppressor proteins (TSPs) such as p53, FOXO, p27 and IkB. However, in PDAC and other cancers, aberrant over-expression of nuclear exporter protein CRM1/Exportin 1/Xpo1 results in mis-localization of
TSPs thereby inhibiting their cell surveillance activity $[3,4]$. Therefore, blocking nuclear export machinery could become a viable therapeutic strategy to restore tumor suppressor functions as well as the apoptosis machinery [5] .

Over-expression of nuclear Notch1 mediated signaling in PDAC has been well established [6,7]. Notch1 carries a large single-pass type 1 trans-membrane receptor that is activated by interaction with membrane bound ligands [8]. For activation Notch1 receptors undergo series of proteolytic cleavage resulting in the activation of Notch1 intracellular domain (Notch1-IC) that translocates into the nucleus [9]. The active forms of Notch1, along with other transcription factors, regulate the expression 
of many tumor promoting genes [10]. Fbw7 (also known as Fbxw7, SEL-10, hCdc4, or hAgo) is the F-box protein subunit of a Skp1-Cul1-F-box protein (SCF)-type ubiquitin ligase complex that plays an important role in the degradation of Notch family members including the activated Notch1C in the nucleus $[11,12]$. Nevertheless, mislocalization of Fbw 7 by CRM1 over-expression results in Notch1 nuclear accumulation and consequent activation of tumor promoting pathways. Therefore, we hypothesize that CRM1 inhibition could potentially restore nuclear Fbw7 leading to degradation of nuclear Notch1 thereby inducing PDAC cell death.

Using structure based drug design, we have recently developed specific inhibitors of nuclear export (SINE Fig 1A \& B). NCI 60 cell line screening shows that the inhibitors have broad tumor specificity and low nano molar potency. Recently, we showed that SINE can suppress proliferation of PDAC [13] and NHL [14] cell lines and induce tumor growth arrest in their corresponding sub-cutaneous and orthotopic tumor models. Most significantly, SINEs do not induce growth inhibition and apoptosis in normal peripheral lymphocytes, NIH-3T3 cells or mouse fibroblast. Additionally, SINEs have excellent pharmacokinetic parameters, have passed advanced toxicity profiling and are currently in phase I clinical trials for solid tumors and hematological malignancies. Using these promising inhibitors, in this study, we investigated their mechanism of action in a panel of PDAC lines and animal tumor model explained in the light of Fbw7-Notch.

\section{RESULTS}

\section{Effects of KPT-185 on the viability of pancreatic cancer cells}

In order to investigate the effect of KPT-185 on cell growth, we evaluated the cell viability of PDAC cells treated with KPT-185 for 72 hrs using the MTT assay. As

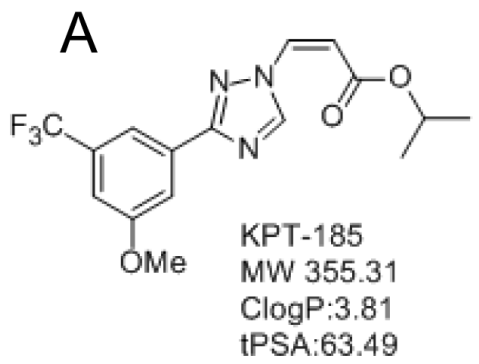

presented in Figure 2 A. KPT-185 inhibits cell growth in a dose dependent manner in all the three cell lines $\left(\mathrm{IC}_{50 \mathrm{~s}}\right.$ $\sim 150 \mathrm{nM}$ ). To confirm the effects of KPT-185 on cell growth, clonogenic assay was performed. Fig $2 \mathrm{~B}$ and C show a dose dependent inhibition of clonogenic potential by KPT-185 in Colo-357 and BxPC-3 cells. The results from the clonogenic assay were consistent with the MTT data shown suggesting that KPT-185 inhibited cell growth in BxPC-3, Colo-357 PDAC cells.

\section{Inhibition of cell migration and invasion by KPT- 185}

Notch over-expressing cells such as BxPC-3 and Colo-357 demonstrate high proliferation and migratory properties. In order to examine whether KPT-185 can prevent their migratory and invasive potential, we conducted wound healing and invasion assays. As shown in Fig. 3 A, KPT-185 inhibited cell migration in a dose dependent manner in both BxPC-3 and Colo-357 PDAC cells. The results of Fig. 3 B clearly show that KPT-185 treated BxPC-3 and Colo-357 cells decrease in their invasive capability as compared to the untreated control. These results confirm that KPT-185 can inhibit cell migration and invasion and whether this results in cell growth arrest was investigated as shown below.

\section{KPT-185 induces cell cycle arrest in PDAC cells}

In order to verify whether KTP-185 works by abrogating cell cycle progression, propidium iodide flow cytometry assays were performed. BxPC-3 cells were exposed to 75 and $100 \mathrm{nM}$ of KPT-185 for $72 \mathrm{hrs}$ and analyzed for cell cycle distribution. As expected, increasing concentrations of KPT-185 resulted in G2-M arrest patterns (Fig 4). Similar results were obtained for Colo-357 cells (data not shown). These findings further solidify the case for KPT-SINEs as effect agents against PDAC. We further investigated the apoptotic potential and also evaluated the mechanism supporting KPT-185

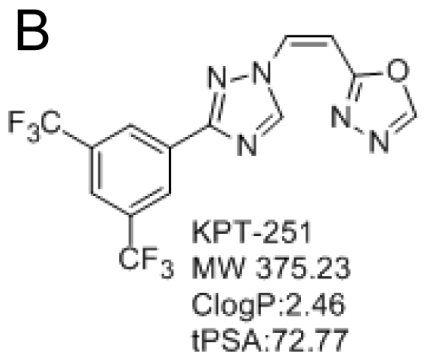

Figure 1: Structures of A. KPT-185 and B. KPT-251 
A

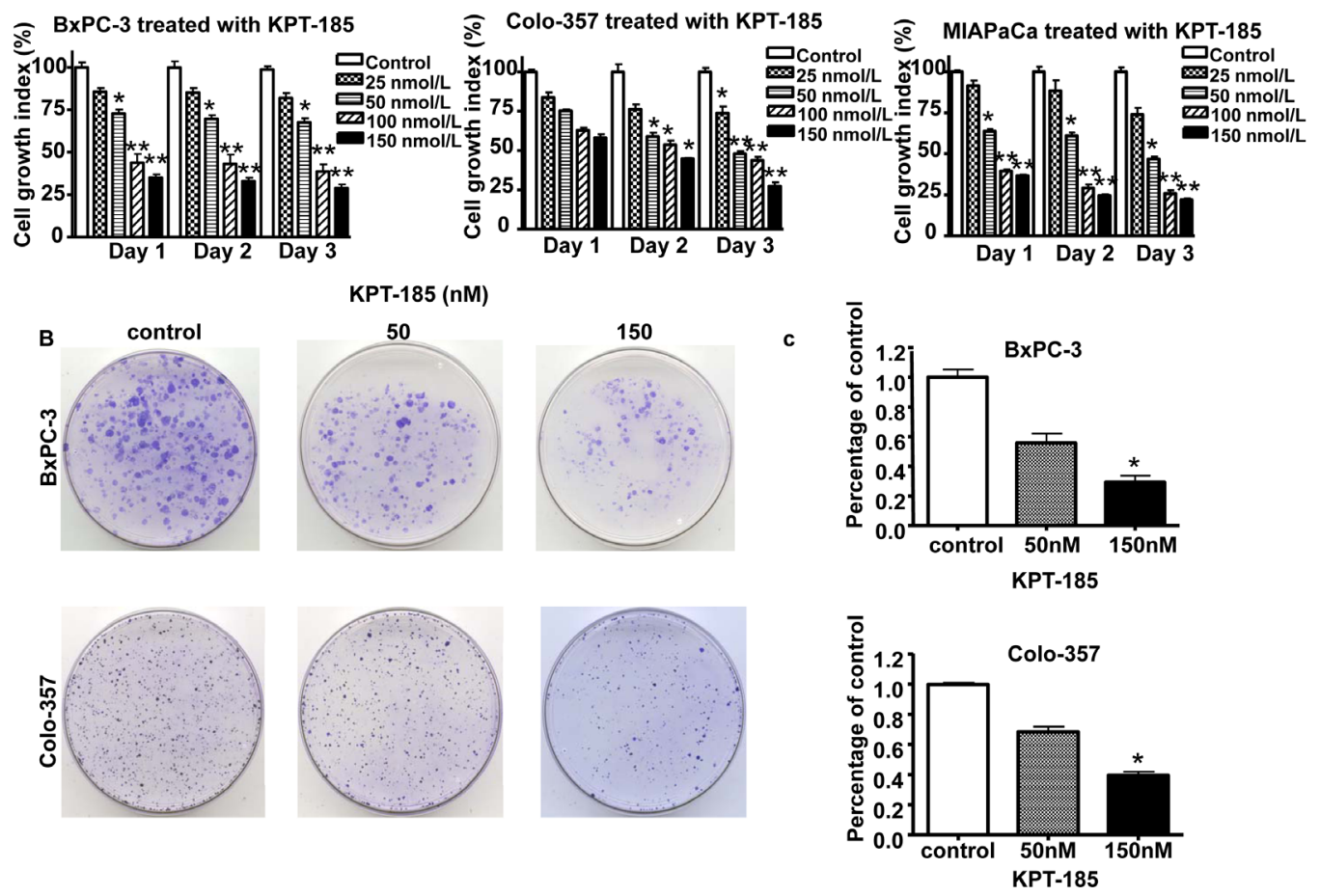

Figure 2: Effects of KPT-185 on PC cell growth. A. BxPC-3, Colo-357 and MIAPaCa cells were seeded in 96-well plates at a density of 5,000 cells per well and treated with the indicated concentrations of KPT-185 for 0-72 hrs. After treatment, cell viability was determined using the MTT assay as described in Materials and Methods. Vertical bars indicate the means \pm SD of three independent experiments. $* p<0.05, * * p<0.01$ versus control. B. Cells treated with different concentrations of KPT-185 for $72 \mathrm{~h}$ were evaluated by the clonogenic assay. Photographic difference in colony formation in BxPC-3 and Colo-357 untreated and treated with KPT-185 are shown. C. Quantification of colony numbers in control vs treated BxPC-3 and Colo-357 cells shown in B. * $p$ values represent comparisons between cells treated by KPT-185 and control using the paired $t$ test.
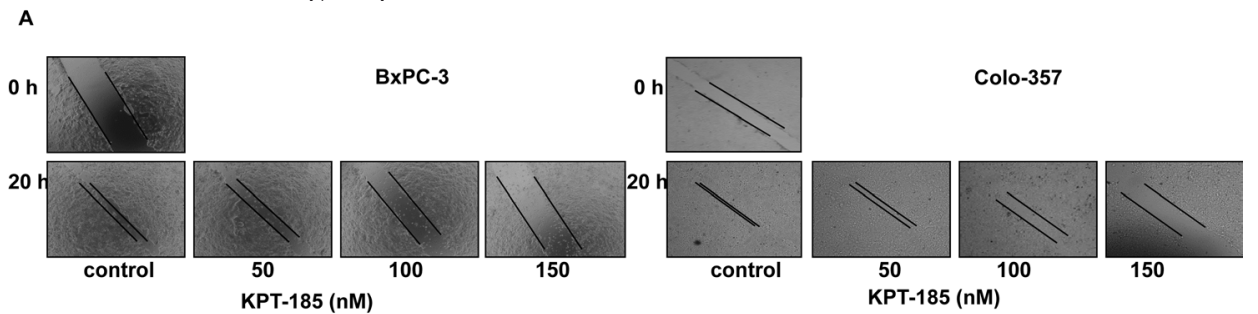

B
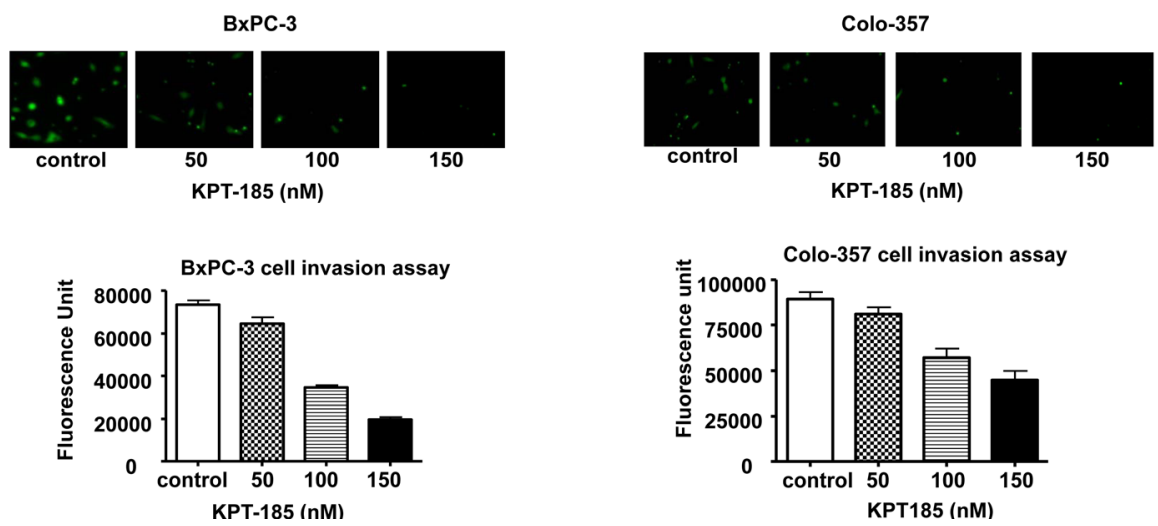

Figure 3: KPT-185 inhibits PC cell migration and invasion. A Dose-dependent inhibition of PC cell migration was observed by KPT-185 using the wound healing assay. The wound was generated in the cells with $90-95 \%$ confluent by scratching the surface of the plates with a sterile pipette tip. The cells were then incubated in the absence and presence of KPT-185 for $20 \mathrm{~h}$; wound healing images were captured by a Nikon microscope. B. Dose-dependent inhibition of PC cells invasion by KPT-185. Cells that invaded to the lower surface of the insert over a period of $20 \mathrm{~h}$ were stained with calcein AM. The fluorescently labeled invasive cells were photographed by a fluorescent microscope. The fluorescence of the invaded cells was read in ULTRA Multifunctional Microplate Reader (TECAN, Switzerland) at excitation/emission wavelengths of $485 / 530 \mathrm{~nm}$. Columns, mean; bars, SD. 
activity and the results are presented below.

\section{KPT-185 induces apoptosis in PDAC cell lines}

In order to verify that growth inhibition by KPT-185 in PDAC is due to induction of apoptosis Histone DNA ELISA assays were performed. Histone DNA ELISA is a highly sensitive assay that quantitatively measures apoptotic cell death. As demonstrated in Fig. 5 and in line with the MTT and colonogenic assays, increasing concentrations of KPT-185 induced a progressive increase in apoptosis in three PC cell lines BxPC-3 (Fig. 5 A), MIAPaCa (Fig. 5 B) and Colo-357 (Fig. 5 C). These results confirm that KPT-185 is a potent apoptosis inducer in PC and we further sought to investigate its mechanism of action as presented below.

\section{KPT-185 targets Fbw7-Notch Axis in PDAC}

To further understand the molecular mechanism involved in KPT-185 induced cell growth inhibition, cell cycle arrest and apoptosis, alterations in the cell survival pathway were investigated using Western blot analysis with especial emphasis on Notch1 signaling. BxPC-3 and Colo-357 cell lines treated with KPT-185 for $72 \mathrm{hrs}$ were assessed using real-time reverse transcription-PCR (RT-PCR) analysis. As shown in Fig. 6 A, the mRNA expression of Hes1 gene decreased after KPT-185 treatment in both cell lines. Additionally the effect of KPT185 on Fbw7 nuclear export in PC cells was assessed by subjecting nuclear extracts from KPT-185 treated BxPC-3 and Colo-357 cells to Western blotting. As shown in Fig. $6 \mathrm{~B}$, compared to control, KPT-185 treatment $(0-150 \mathrm{nM})$, leads to significantly enhanced accumulation of Fbw7 with concomitant down-regulation of Notch1 protein. Most significantly, we also observed down-regulation of Notch pathway proteins (Hes-1, C-myc, VEGF and CyclinD). These results solidify our hypothesis that KPT-185 works through nuclear retention of the Notch suppressor Fbw7. Based on these strong in vitro findings we investigated the in vivo potential of analog KPT-251 in xenograft developed from Colo-357 cell lines.
0

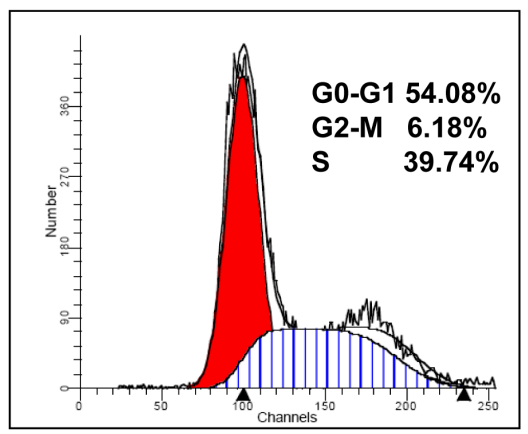

KPT-185 (nM)

75

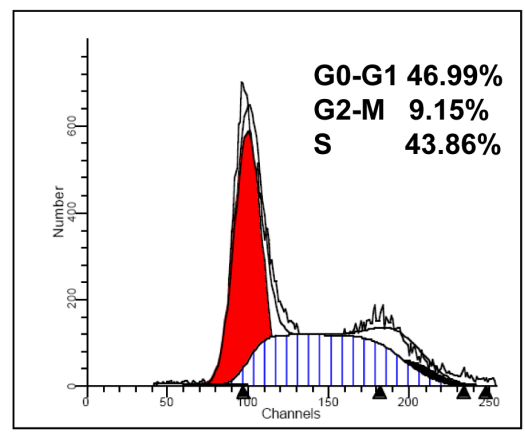

BxPC-3

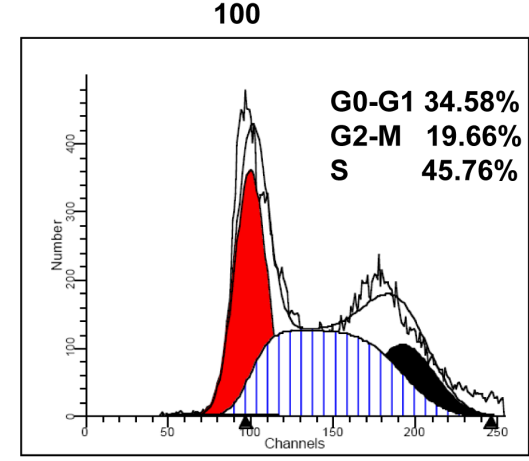

Figure 4:KPT-185 induces cell cycle arrest at G2-M phase. BxPC-3 cells were exposed to the indicated concentrations $(0,75$, $100 \mathrm{nM}$ ) of KPT-185 for $72 \mathrm{hrs}$ and cells were harvested for cell cycle analysis using propidium iodide staining. X axis, DNA content; Y axis, number of nuclei.
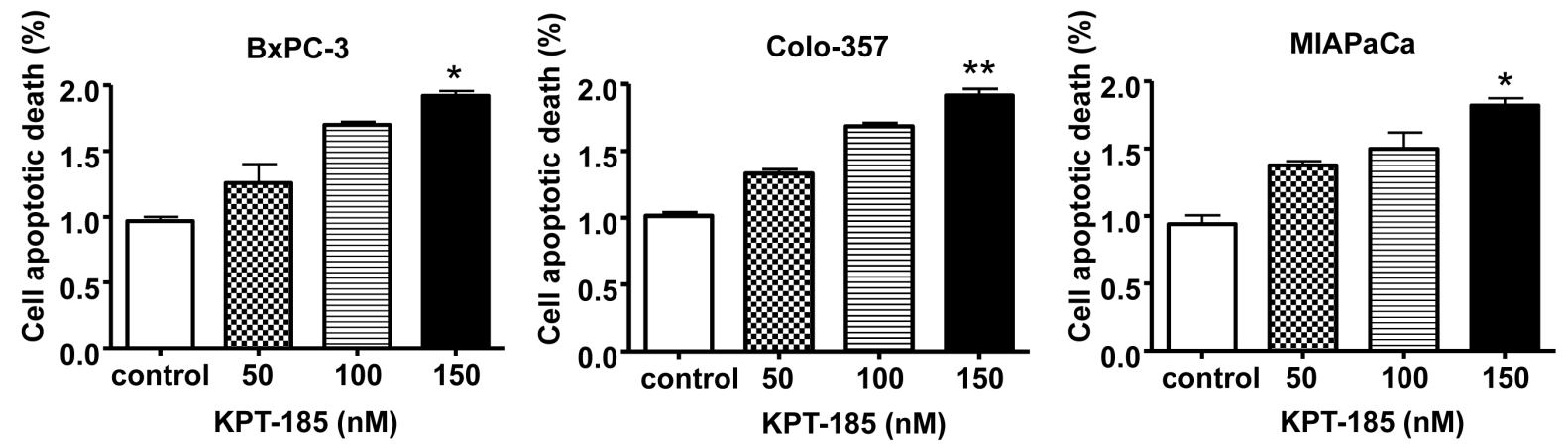

Figure 5: KPT-185 induces apoptosis in PC cells. BxPC-3, Colo-357 and MIAPaCa cells were exposed to different concentrations of KPT-185 for $72 \mathrm{~h}$. Apoptosis were determined by histone/DNA ELISA. Columns, mean; bars, SD. $* p<0.05, * * p<0.01$, compared with control. 


\section{Pre-clinical efficacy trial of KPT-SINE}

For in vivo studies we challenged SCID mice carrying Colo-357 sc tumors with the orally available analog KPT-251 (Fig 7 A for schema of treatment). SINEs have been developed as safe anti-tumor agents for cancer therapy and do not show toxicity. Body weight of the host animal remains stable during the course of treatment with the Maximum tolerated dose (MTD) of KPT-251, calculated to be $75 \mathrm{mg} / \mathrm{kg}$ sc for 20 days, (Fig 7 B). Most significantly, and in line with the in vitro results, oral administration of KPT-251 at $75 \mathrm{mg} /$ $\mathrm{kg}$ resulted in drastic tumor regression in the Colo-357 animal models (Fig $7 \mathrm{C}$ ). To further investigate whether KPT-251 down-regulates Notch1 in vivo, we examined Notch1 expression in tumor tissues obtained from KPT251-treated animals. As expected, Western blot analyses of animal tissues demonstrated significant down-regulation of Notch1 and its related proteins (c-myc and VEGF Fig 7 D). Interestingly, we observed induction of Fbw7 and suppression of Notch1 in KPT-251 treated tumors (Fig. 7 E). These data show that KPT holds strong anti-tumor potential and warrant further clinical application for the treatment of PDAC.

\section{DISCUSSION}

This study shows that CRM1 inhibition and consequent nuclear retention of tumor suppressor proteins by specific inhibitors of nuclear export could become a therapeutic strategy for PDAC. Mechanistically we have discovered that our CRM1 inhibitors work through a novel Fbw7 nuclear retention mediated notch1 suppressive mechanism that could be replicated both in vitro and in vivo. Based on these strong pre-clinical findings, we propose that our novel CRM1 inhibitors hold strong translational potential and warrant further clinical investigations in PDAC.

The majority of PC patients are intractable to currently available treatment modalities [15]. A major reason for failure chemotherapeutic agents such as gemcitabine, platinum based drugs and $5 \mathrm{FU}$ has been attributed to inadequate activation of tumor suppressor proteins [16]. In instances where TSPs are activated, their function is inhibited by mislocalization through constant nuclear export by CRM1 protein [17]. CRM1 is the major TSPs and its importance can be gauged by the observation that the protein is found over-expressed in most cancers including PDAC [3]. Therefore, targeted inhibition of the nuclear exporter CRM1 becomes an attractive therapeutic strategy for the treatment of PC. Earlier attempts to target

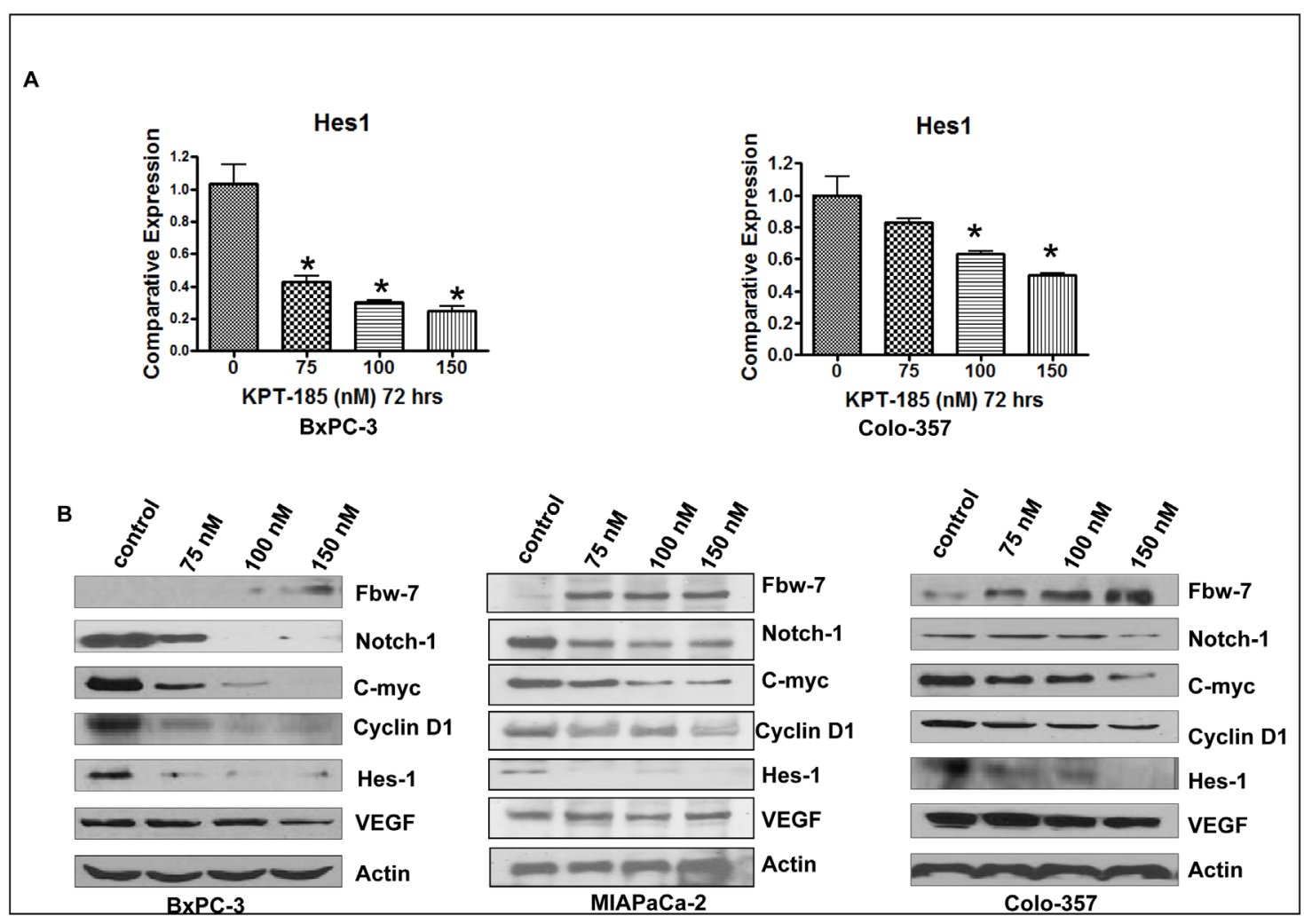

Figure 6: KPT-185 Targets Fbw7-Notch axis in PC. A. The mRNA levels of Hes-1 was investigated by real-time RT-PCR in BxPC-3 and Colo-357 PC cells treated with KPT-185 for 72 h. Columns, mean; bars, SD. ${ }^{*} p<0.05$, ${ }^{*} p<0.01$, compared with the control. B. Nuclear protein levels of Fbw7, Notch1, C-myc, CyclinD1, Hes-1 and VEGF detected by Western blotting in BxPC-3 and Colo-357 PC cells treated with KPT-185 (0-150 nM) for $72 \mathrm{hr}$. 
CRM1 led to development of agents such as Leptomycin B (LMB), although specific inhibitors of CRM1, yet showed adverse off target toxicities [18].

To overcome toxicity, we have developed novel highly specific non-toxic small molecules capable of antagonizing the functions of CRM1 [19]. Unlike, Leptomycin B that form an irreversible covalent bond with Cys528 of CRM1, KPT-185 bind to CRM1 in a slowly reversible fashion, which might contribute to the improved tolerability of the SINE compounds. SINE block nuclear export of TSPs thereby inducing growth inhibition and apoptosis specifically in cancer cells [20,21,22,23,24,25,26,27,28]. Earlier, our group has studied the impact of CRM1 inhibtion in PDAC models and the downstream signaling analysis [13]. These studies deciphered the downstream targets including FOXO3a, p27, p21 and the pro-apoptotic protein prostate apoptosis response 4 (PAR-4) mediated effects both in vitro as well as in animal models of PDAC. In the current study, we investigated the anti-tumor potential and molecular mechanism of action by which our CRM1 inhibitors elicit their biological effects in PDAC cells and tumor models. The lead CRM1 inhibitor KPT-185 effectively caused growth inhibition, suppressed colonogenic potential and induced G2-M cell cycle arrest and apoptosis in a panel of PDAC cell lines. As such these investigations proved the potential of KPT-185 as new anti-cancer agents for PDAC.

The TSP Fbw7, among the nuclear export targets of CRM1, plays a central role in the degradation of Notch family members. Fbw7 has been recently shown to exert its anti-tumor effects through degradation of Notch1 [29]. Some reports have shown that Fbw7 binds to phosphorylated Notch $1 \mathrm{C}$ and mediates its ubiquitination and subsequent rapid degradation [30]. Additionally, Fbw7 exerts its inhibitory effect by regulating Notch1 downstream signaling pathways through ubiquitin ligase mediated degradation [31]. However, there are no available agents that enhance FBW7 or induce its nuclear retention. These key observations led to our hypothesis that targeted inhibition of CRM1 and nuclear retention of Fbw 7 could become a viable therapeutic strategy for PDAC. In line with our hypothesis we observed that

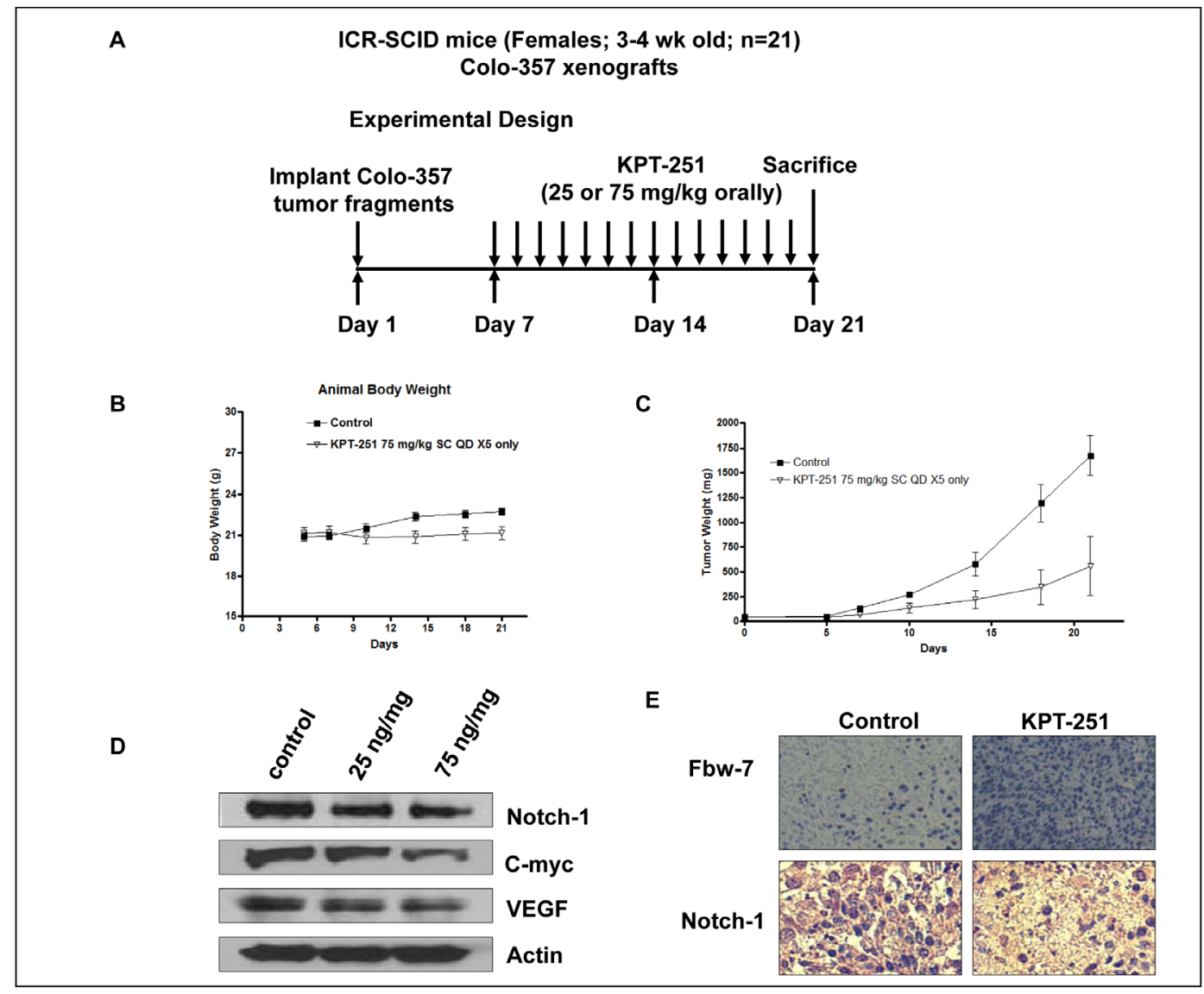

Figure 7: In vivo anti-tumor efficacy and molecular mechanism of action of KPT-251. A. Schematic representation of the experimental design. B. KPT-251 treated ICR SCID animal body weight loss evaluation. Note: no statistically significant loss in body weight on KPT-251 treatment. The MTD was determined to be $75 \mathrm{mg} / \mathrm{kg} \mathrm{sc}$. C. Efficacy trial of KPT- 251 treated at $75 \mathrm{mg} / \mathrm{kg}$ bw daily for 2 weeks. Note KPT-251 treatment drastically reduced tumor growth in comparison to control. D. The expression of Notch1, C-myc and VEGF was detected by Western blotting of tumor tissue extracts. E. immunohistochemical staining of Colo-357 tumor xenografts. Tumors were resected and processed for routine histologic analysis and the $5 \mu \mathrm{mol} / \mathrm{L}$ tissue sections were stained with antibodies to Notch1 and Fbw7. 
treatment with KPT-185 resulted in nuclear accumulation of Fbw7 with consequent down-regulation of Notch1 and related pathways (Hes-1, C-Myc and VEGF) in PDAC cells and this was correlated with our growth inhibition, cell cycle arrest and apoptosis data.

Prior to clinical application of a new therapeutic agent, such as SINEs, pre-clinical evaluation in a suitable animal model is required. Therefore, we tested the in vivo potential of the drugs in xenograft models derived from Colo-357 cells that are recognized to over-express Notch. In line with our in vitro growth inhibition and apoptosis results, the analog KPT-251 showed remarkable anti-tumor activity in the Colo-357 model and most importantly had no visible toxicity to host animals. Of paramount significance is the observation that in residual tumors we could replicate the in vitro mechanistic findings and observed clear activation of Fbw 7 and suppression of Notch signaling.

In summary, we have provided experimental evidence that supports the role of SINEs as antitumor agent for PDAC. Mechanistically, we propose that our SINEs attenuate Notch1 signaling, cell proliferation, invasion and induce apoptosis in PC cells by degradation of Notch1 through nuclear retention of Fbw7 (Synopsis graphical abstract for summary mechanistic schema). However, further studies are needed to confirm the molecular regulation of Notch1 by SINE induced-Fbw7 expression prior to their clinical application for PDAC.

\section{MATERIALS AND METHODS}

\section{Cell culture and experiment reagents.}

Human PDAC cell lines BxPC-3, Colo-357 and MIAPaCa used in this study were obtained from ATCC and maintained in standard cell culture conditions (at $37{ }^{\circ} \mathrm{C}$ in a humidified $5 \% \mathrm{CO}_{2}$ atmosphere). Primary antibody for Notch1, CyclinD1, VEGF were purchased from Santa Cruz Biotechnology (Santa Cruz, CA), Fbw7 and Hes-1 were purchased from the Abcam (San Francisco, CA), C-myc, Bcl-2 were purchased from Cell signaling (Danvers, MA). The secondary antibodies were bought from Sigma (St. Louis, MO). SINEs (KPT-185 and KPT-251) were designed, synthesized and purified by Karyopharm Therapeutic (Natick, MA).

\section{Cell viability Studies by MTT assay.}

The BxPC-3, Colo-357 and MIAPaCa cells $\left(5 \times 10^{3}\right)$ were seeded in a 96-well culture plate. $24 \mathrm{hrs}$ after seeding, cells were treated with various concentrations of most potent KPT-SINE KPT-185 for 24, 48, and 72 hrs. At the end of treatment period, $10 \mathrm{uL}$ of Reagent MTT (Sigma Chemical Company $5 \mathrm{mg} / \mathrm{mL}$ in PBS) was added to each well. After 2 hrs incubation $100 \mu \mathrm{L}$ of Isopropanol was added to each well and further incubated for 20 minutes

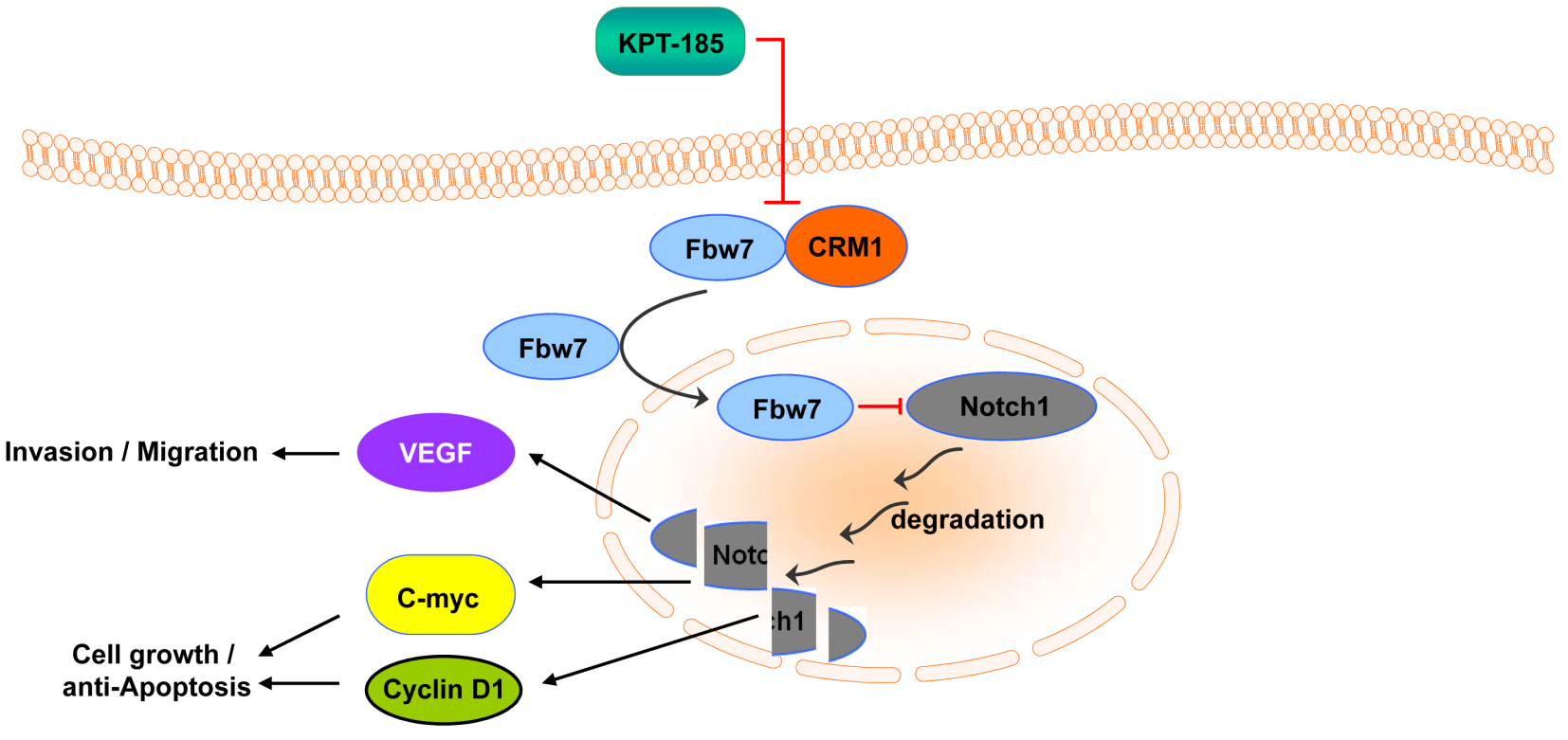

Figure 8: Summary Schema. Chromosome maintenance region 1 (CRM1) is the major nuclear exporter of tumor suppressor proteins (TSPs) and has been considered as a therapeutic target in cancer. We have developed a specific inhibitor of nuclear export (SINE) that blocks CRM1 leading to restoration of important TSPs in cancer cell nucleus. Mechanistically, we show that our SINEs attenuate Notch1 signaling, cell proliferation, invasion and induce apoptosis in a pancreatic cancer model by degradation of Notch1 through nuclear retention of Fbw7. The schematic representation of the proposed molecular mechanism of SINE induced pancreatric cancer cell growth inhibition and apoptosis. 
in dark. The color intensity was measured by TECAN's microplate fluorometer (TECAN Switzerland) at $595 \mathrm{~nm}$.

\section{Clonogenic assay.}

To test the survival of cells treated with KPT-185, BxPC- 3 and Colo- 357 cells were plated $\left(3 \times 10^{5}\right.$ per well) in a six-well plate and incubated overnight. After $72 \mathrm{hrs}$ exposure to various concentrations of KPT-185, the viable cells were counted and plated in $100 \mathrm{~mm}$ dishes in a range of 3,000 cells per plate. The cells were then incubated for 21 days at $37{ }^{\circ} \mathrm{C}$ in a humidified $5 \% \mathrm{CO}_{2}$ atmosphere. All the colonies were fixed in $4 \%$ Paraformaldehyde and stained with $2 \%$ crystal violet.

\section{Wound healing assay}

Wound healing assay was conducted to examine the capacity of cell migration. BxPC-3 and Colo-357 were seeded in a six well plate at the concentration of $3 \times 10^{5}$ cells per well. The wound was generated in the cells with $90-95 \%$ confluent by scratching the surface of the plates with a sterile pipette tip. The cells were then incubated in the absence and presence of KPT-185 for $20 \mathrm{hrs}$, and then photographed with a Nikon microscope.

\section{Cell invasion assay}

BD Biocoat invasion kit (BD, San Jose, CA) was used to evaluate the tumor invasive ability. Briefly, around $2.5 \times 10^{4}$ cells of BxPC-3 and Colo-357 with basal media was transferred in each 6-well upper chamber in the presence or absence of KPT-185. 0.75 milliliter of culture medium with $5 \%$ FBS was added into each bottom chamber of 6-well plate. After $20 \mathrm{hrs}$ of incubation, the cells in the upper chamber were removed, and the cells that had invaded through Matrigel matrix membrane were stained with $4 \mu \mathrm{g} / \mathrm{mL}$ calcein AM in PBS at $37^{\circ} \mathrm{C}$, $5 \% \mathrm{CO}_{2}$ for $1 \mathrm{hr}$. The fluorescence of the invaded cells was read in ULTRA Multifunctional Microplate Reader (TECAN, Switzerland) at excitation/emission wavelengths of $485 / 530 \mathrm{~nm}$. These fluorescently labeled invasive cells were also photographed under a fluorescent microscope.

\section{Flow cytometry and cell cycle analysis.}

Cells were seeded in $100 \mathrm{~mm}$ dish per plate, incubated overnight. Subsequently, all the cells were serum starved for another $24 \mathrm{hrs}$. The cells were exposed vehicle (DMSO) or KPT-185 and grown for $72 \mathrm{hr}$. At the end of treatment period, cells were collected and fixed with ice-cold $70 \%(\mathrm{v} / \mathrm{v})$ ethanol for $24 \mathrm{hr}$. After centrifugation at $3000 \times \mathrm{g}$ for $5 \mathrm{~min}$, the cell pellets were washed with PBS (pH 7.4) and resuspended in PBS containing propidium iodide (50 $\mu \mathrm{g} / \mathrm{mL})$, and DNase-free RNase A $(100 \mu \mathrm{g} / \mathrm{mL})$. Samples were then incubated at 37 ${ }^{\circ} \mathrm{C}$ for 15 min, and DNA contents were determined by flow cytometry using a flow cytometer (BD, San Jose, CA) by the Karmanos Cancer Institute Flow cytometry core.

\section{Histone/DNA ELISA for detection of apoptosis.}

The Cell Death Detection ELISA Kit (Roche Applied Science, Indianapolis, IN) was used to detect apoptosis in pancreatic cells. $3 \times 10^{5}$ cells were seeded in six-well plates. After 24 hrs incubation, cells were treated with various concentrations of KPT-185 for $72 \mathrm{hrs}$. The cells were then lysed, and cytoplasmic histone/DNA fragments were extracted and incubated in microtiter plate modules coated with anti-histone antibody. In order to detect the immobilized histone/DNA fragment, Peroxidase-conjugated anti-DNA antibody was used before color development with ABTS substrate for peroxidase. The spectrophotometric absorbance of the sample was determined by TECAN's microplate fluorometer (TECAN, Switzerland) at $405 \mathrm{~nm}$.

\section{Protein extraction and western blotting}

For protein extraction, KPT-185 treated cells were sonicated in $125 \mathrm{mM}$ Tris- $\mathrm{HCl}$ and $4 \%$ SDS according to our previously published methods [32]. In another set of experiments, cytoplasmic and nuclear proteins were also extracted using NE-PER Nuclear and Cytoplasmic Extraction Reagents (Thermo Scientific, Rockford, IL). The protein concentrations were determined using the $\mathrm{BCA}^{\mathrm{TM}}$ protein assay reagent (Thermo Scientific, Rockford, IL). Proteins were fractionated using sodium dodecyl sulfate-polyacrylamide gel electrophoresis (SDSPAGE), and the gels were transferred onto nitrocellulose membrane. The membranes were blocked with $4 \%$ nonfat dried milk or bovine serum albumin in $1 \times \mathrm{PBS}$ containing $0.1 \%$ Tween-20 and then incubated over night at $4{ }^{\circ} \mathrm{C}$ with appropriate primary antibodies. The membranes were washed 3 times with PBS-T, and subsequently incubated with the secondary antibodies for $2 \mathrm{hrs}$ at room temperature. The protein bands were detected using the enhanced chemiluminesence detection system (Genscript, Piscataway, NJ).

\section{Real-time quantitative PCR for gene expression analysis}

The total RNA was isolated by Trizol (Invitrogen, Carlsbad, CA) according to the manufacturer's protocols. Two microgram of total RNA from each sample was subjected to first strand cDNA synthesis using High capacity RNA to cDNA master mix (Life 
Technologies Corporation, CA) in a total volume of $20 \mu \mathrm{L}$. Reverse transcription reaction were performed at $37^{\circ} \mathrm{C}$ for $1 \mathrm{~h}$, followed $95^{\circ} \mathrm{C}$ for $5 \mathrm{~min}$. Real time PCR was used to quantify mRNA expression by using SYBR $^{\circledR}$ Green RT-PCR Reagents (Life Technologies Corporation, CA). Sequences of primers were sets used for this analysis are as follows: Hes-1, forward (AACACGACACCGGATAAACC -3') and reverse primer (5'- CCGCGAGCTATCTTTCTTCA -3'); GAPDH, forward (5'-ACCCAGAAGACTGTGGATGG-3') and reverse primer (5'-CAGTGAGCTTCCCGTTCAG-3'). The PCR were performed in a total of $10 \mu \mathrm{L}$ reaction mixture $(2 \mu \mathrm{L}$ of cDNA, $17 \mu \mathrm{L}$ of $2 \times$ SYBR Green PCR Mix, $1.4 \mu \mathrm{L}$ of each $5 \mu \mathrm{mol} / \mathrm{L}$ forward and reverse primers, and $13.6 \mu \mathrm{L}$ of Nuclease-free water for 3 well) in StepOne Plus Real-Time PCR System (Applied Biosystems, CA). The PCR program was initiated by 10 minutes at $95^{\circ} \mathrm{C}$ before 45 thermal cycles, each for 15 seconds at $95^{\circ} \mathrm{C}$ and 1 minute at $60^{\circ} \mathrm{C}$. Data were analyzed according to the comparative fold increase or decrease in gene expression determined by ct values and normalized by GAPDH expression in each sample.

\section{Colo-357 xenografts}

Four-week-old female ICR-SCID mice were obtained from Taconic Laboratory and xenografts were developed by injecting $10^{7}$ Colo-357 cells s.c. in each flank area. When s.c. tumors developed to about 1,500 $\mathrm{mg}$, the tumors were excised, and serial propagation was accomplished by trimming extraneous material, cutting the tumors into fragments of $50 \mathrm{mg}$, which were then transplanted s.c. into the flanks of a new group of mice for maintenance of tumors as well as for experimental purpose. For the subsequent drug efficacy trials, small fragments of the Colo-357 xenograft were implanted s.c. and bilaterally into naive, similarly adapted mice $(n=20)$. Mice were checked 3 times per week for tumor development. Once transplanted, Colo-357 fragments developed into palpable tumors (60-100 mg); animals were removed randomly and assigned to different treatment groups (10 per group). Using this model, the efficacy of KPT-251 (analog of KPT-185, used in vivo) was studied. The maximum tolerated dose of KPT-251 in severe combined immunodeficient mice was determined to be $75 \mathrm{mg} / \mathrm{kg}$. Mice were administered with KPT-251 at 25 or $75 \mathrm{mg} / \mathrm{kg}$ orally, for 2 weeks. (as shown in Fig 6A.). Mice in the control and KPT-251 treated group were followed for measurement of s.c. tumors, changes in body weight and side effects of the drugs. Tumor was calculated using the formula $\left(\mathrm{A} \times \mathrm{B}^{2}\right) / 2$, where $\mathrm{A}$ and $\mathrm{B}$ are the tumor length and width (in $\mathrm{mm}$ ). To avoid discomfort in the control group, animals were euthanized when their total tumor burden reached 2,000 mg. Tumor tissues harvested from this experiment were used for immunohistochemical and Western blotting analyses. All studies involving mice were performed under Animal Investigation Committee approved protocols at Wayne State University.

\section{Immunohistochemical determination of Notch1 and Fbw7.}

The expression of Notch1 and Fbw7 was detected in histologic sections of tumor xenografts. Sections were cut from formalin-fixed, paraffin-embedded tissue blocks; collected on 3-ethoxy-aminoethyl-silane-treated slides; and allowed to dry overnight at $37^{\circ} \mathrm{C}$. Sections were dewaxed in xylene, rehydrated through graded concentrations of ethanol to distilled water, immersed in $10 \mathrm{mmol} / \mathrm{L}$ citrate buffer ( $\mathrm{pH}$ 6.0), and processed in a thermostatic water bath for 40 minutes at $98^{\circ} \mathrm{C}$ for antigen retrieval. Anti-Notch 1 , and anti-Fbw7 antibodies were applied on two slides for each case, and incubations were done overnight at room temperature in a humidified atmosphere followed by a 30-minute incubation of secondary antibody. Slides were then incubated with streptavidin peroxidase and visualized using the 3,3'-diaminobenzidine chromogen (Lab Vision Corp., Fremont, CA).

\section{Tumor Tissue proteins isolation and western blot analysis:}

At the end of the treatment period tumors were excised and one part was minced for protein isolation according to our previously published methods. $100 \mu \mathrm{g}$ tumor protein lysates were resolved using western blotting assay. The membranes were probed for Notch1, C-myc, VEGF and $\beta$-actin.

Data Analysis: Data are represented as mean \pm SD for the absolute values or percentage of controls as indicated in the vertical axis legend of figures. The statistic significance of differential findings between experimental groups and control groups was statistically evaluated ANOVA using GraphPad StatMate software (GraphPad Software, Inc., San Diego, CA). $p$ values lower than 0.05 were considered statistically significant.

\section{ACKNOWLEDGEMENTS}

NIH R21 1R21CA16984801 and 1R21CA17597401 to RMM is acknowledged. We acknowledge Karyopharm Therapeutic for funding this study. We also acknowledge the financial support provided through China Scholarship Council (CSC).

\section{Conflict of Interest Statement:}

Sharon Shacham and Michael Kauffman hold equity in Karyopharm Therapeutics. 


\section{REFERENCES}

1. Siegel R, Naishadham D, Jemal A, Cancer statistics, 2013, CA Cancer J Clin 2013, 63:11-30

2. Wang Z, Li Y, Ahmad A, Banerjee S, Azmi AS, Kong D, Sarkar FH, Pancreatic cancer: understanding and overcoming chemoresistance, Nat Rev Gastroenterol Hepatol 2011, 8:27-33

3. Huang WY, Yue L, Qiu WS, Wang LW, Zhou XH, Sun YJ, Prognostic value of CRM1 in pancreas cancer, Clin Invest Med 2009, 32:E315

4. Turner JG, Sullivan DM, CRM1-mediated nuclear export of proteins and drug resistance in cancer, Curr Med Chem 2008, 15:2648-2655

5. Mao L, Yang Y, Targeting the nuclear transport machinery by rational drug design, Curr Pharm Des 2013, 19:23182325

6. Miele L, Golde T, Osborne B, Notch signaling in cancer, Curr Mol Med 2006, 6:905-918

7. Miele L, Notch signaling, Clin Cancer Res 2006, 12:10741079

8. Kopan R, Cagan R, Notch on the cutting edge, Trends Genet 1997, 13:465-467

9. rtavanis-Tsakonas $\mathrm{S}$, Rand MD, Lake RJ, Notch signaling: cell fate control and signal integration in development, Science 1999, 284:770-776

10. Wang Z, Banerjee S, Li Y, Rahman KM, Zhang Y, Sarkar FH, Down-regulation of notch-1 inhibits invasion by inactivation of nuclear factor-kappaB, vascular endothelial growth factor, and matrix metalloproteinase-9 in pancreatic cancer cells, Cancer Res 2006, 66:2778-2784

11. Minella AC, Clurman BE, Mechanisms of tumor suppression by the SCF(Fbw7), Cell Cycle 2005, 4:13561359

12. Babaei-Jadidi R, Li N, Saadeddin A, Spencer-Dene B, Jandke A, Muhammad B, Ibrahim EE, Muraleedharan R, Abuzinadah M, Davis H, Lewis A, Watson S, Behrens A, Tomlinson I, Nateri AS, FBXW7 influences murine intestinal homeostasis and cancer, targeting Notch, Jun, and DEK for degradation, J Exp Med 2011, 208:295-312

13. Azmi AS, Aboukameel A, Bao B, Sarkar FH, Philip PA, Kauffman M, Shacham S, Mohammad RM, Selective Inhibitors of Nuclear Export Block Pancreatic Cancer Cell Proliferation and Reduce Tumor Growth in Mice, Gastroenterology 2012, 44: 447-456

14. Azmi AS, Al-Katib A, Aboukameel A, McCauley D, Kauffman M, Shacham S, Mohammad RM, Selective inhibitors of nuclear export for the treatment of nonHodgkin's Lymphomas, Haematologica 2013, 98:10981106

15. Gieseler F, Rudolph P, Kloeppel G, Foelsch UR, Resistance mechanisms of gastrointestinal cancers: why does conventional chemotherapy fail?, Int J Colorectal Dis 2003, $18: 470-480$
16. Gieseler F, Rudolph P, Kloeppel G, Foelsch UR, Resistance mechanisms of gastrointestinal cancers: why does conventional chemotherapy fail?, Int J Colorectal Dis 2003, 18:470-480

17. Turner JG, Dawson J, Sullivan DM, Nuclear export of proteins and drug resistance in cancer, Biochem Pharmacol 2012, 83:1021-1032

18. Newlands ES, Rustin GJ, Brampton MH, Phase I trial of elactocin, Br J Cancer 1996, 74:648-649

19. Kalid O, Toledo WD, Shechter S, Sherman W, Shacham $\mathrm{S}$, Consensus Induced Fit Docking (cIFD): methodology, validation, and application to the discovery of novel Crm1 inhibitors, J Comput Aided Mol Des 2012, 26:1217-1228

20. Salas Fragomeni RA, Chung HW, Landesman Y, Senapedis W, Saint-Martin JR, Tsao H, Flaherty KT, Shacham S, Kauffman M, Cusack JC, CRM1 and BRAF inhibition synergize and induce tumor regression in BRAF mutant melanoma, Mol Cancer Ther 2013,

21. Tai YT, Landesman Y, Acharya C, Calle Y, Zhong MY, Cea M, Tannenbaum D, Cagnetta A, Reagan M, Munshi AA, Senapedis W, Saint-Martin JR, Kashyap T, Shacham S, Kauffman M, Gu Y, Wu L, Ghobrial I, Zhan F, Kung AL, Schey SA, Richardson P, Munshi NC, Anderson $\mathrm{KC}, \mathrm{CRM} 1$ inhibition induces tumor cell cytotoxicity and impairs osteoclastogenesis in multiple myeloma: molecular mechanisms and therapeutic implications, Leukemia 2013, 28:155-165

22. Muqbil I, Kauffman M, Shacham S, Mohammad RM, Azmi AS, Understanding XPO1 Target Networks Using Systems Biology and Mathematical Modeling, Curr Pharm Des 2013, 20: 56-65

23. Etchin J, Sanda T, Mansour MR, Kentsis A, Montero J, Le BT, Christie AL, McCauley D, Rodig SJ, Kauffman M, Shacham S, Stone R, Letai A, Kung AL, Thomas LA, KPT330 inhibitor of CRM1 (XPO1)-mediated nuclear export has selective anti-leukaemic activity in preclinical models of T-cell acute lymphoblastic leukaemia and acute myeloid leukaemia, Br J Haematol 2013, 161:117-127

24. Inoue H, Kauffman M, Shacham S, Landesman Y, Yang J, Evans CP, Weiss RH, CRM1 Blockade by Selective Inhibitors of Nuclear Export Attenuates Kidney Cancer Growth, J Urol 2012, 189: 2317-2326

25. Lapalombella R, Sun Q, Williams K, Tangeman L, Jha S, Zhong Y, Goettl V, Mahoney E, Berglund C, Gupta S, Farmer A, Mani R, Johnson AJ, Lucas D, Mo X, Daelemans D, Sandanayaka V, Shechter S, McCauley D, Shacham S, Kauffman M, Chook YM, Byrd JC, Selective inhibitors of nuclear export show that CRM1/XPO1 is a target in chronic lymphocytic leukemia, Blood 2012, 120:4621-4634

26. Zhang K, Wang M, Tamayo AT, Shacham S, Kauffman M, Lee J, Zhang L, Ou Z, Li C, Sun L, Ford RJ, Pham LV, Novel selective inhibitors of nuclear export CRM1 antagonists for therapy in mantle cell lymphoma, Exp Hematol 2013, 41:67-78 
27. Etchin J, Sun Q, Kentsis A, Farmer A, Zhang ZC, Sanda T, Mansour MR, Barcelo C, McCauley D, Kauffman M, Shacham S, Christie AL, Kung AL, Rodig SJ, Chook YM, Look AT, Antileukemic activity of nuclear export inhibitors that spare normal hematopoietic cells, Leukemia 2013, 27:66-74

28. Ranganathan P, Yu X, Na C, Santhanam R, Shacham S, Kauffman M, Walker A, Klisovic R, Blum W, Caligiuri M, Croce CM, Marcucci G, Garzon R, Preclinical activity of a novel CRM1 inhibitor in acute myeloid leukemia, Blood 2012, 120:1765-1773

29. Gupta-Rossi N, Le BO, Gonen H, Brou C, Logeat F, Six E, Ciechanover A, Israel A, Functional interaction between SEL-10, an F-box protein, and the nuclear form of activated Notch1 receptor, J Biol Chem 2001, 276:34371-34378

30. Oberg C, Li J, Pauley A, Wolf E, Gurney M, Lendahl $\mathrm{U}$, The Notch intracellular domain is ubiquitinated and negatively regulated by the mammalian Sel-10 homolog, J Biol Chem 2001, 276:35847-35853

31. Mo JS, Ann EJ, Yoon JH, Jung J, Choi YH, Kim HY, Ahn JS, Kim SM, Kim MY, Hong JA, Seo MS, Lang F, Choi EJ, Park HS, Serum- and glucocorticoid-inducible kinase 1 (SGK1) controls Notch1 signaling by downregulation of protein stability through Fbw7 ubiquitin ligase, J Cell Sci 2011, 124:100-112

32. Azmi AS, Philip PA, Beck FW, Wang Z, Banerjee S, Wang S, Yang D, Sarkar FH, Mohammad RM, MI-219-zinc combination: a new paradigm in MDM2 inhibitor-based therapy, Oncogene 2011, 30:117-126 